\title{
Effects of Activity and Temperature on Aerobic and Anaerobic Metabolism in the Galapagos Marine Iguana*
}

\author{
Albert F. Bennett \\ School of Biological Sciences, University of California, Irvine, California, USA \\ William R. Dawson \\ Department of Zoology, University of Michigan, Ann Arbor, Michigan, USA \\ George A. Bartholomew \\ Department of Biology, University of California, Los Angeles, California, USA
}

Received March 4, 1975

Summary. 1. Standard and maximal levels of oxygen consumption, and lactate production during burst activity were determined in the Galapagos marine iguana, Amblyrhynchus cristatus. This semiaquatic lizard sustains vigorous activity at relatively low body temperatures during underwater feeding $\left(<25^{\circ} \mathrm{C}\right)$.

2. Intense activity can be sustained only briefly, $90 \%$ of the response occurring within 2 min (Fig. 5). The amount of activity elicited by stimulation is independent of body temperature (Fig. 4).

3. Standard oxygen consumption has a strong temperature dependence $\left(Q_{10}=2.9\right)$ over the range studied $\left(24.8-41.6^{\circ} \mathrm{C}\right)$. Oxygen consumption during activity is maximal at $30-40{ }^{\circ} \mathrm{C}$ (Fig. 1).

4. Aerobic scope is maximal at $35^{\circ} \mathrm{C}$, the basking temperature of the species.

5 . The rate of increase of oxygen consumption during activity is temperature dependent (Fig. 2).

6. High concentrations of lactic acid appear in the blood after maximal activity (Fig. 3).

7. An estimated $97-99 \%$ of the carbohydrate catabolized during maximal activity enters anaerobic pathways; 71-92\% of the ATP produced is derived anaerobically.

8. Despite its atypical thermal regime and energetically demanding mode of feeding, Amblyrhynchus displays a metabolic pattern similar to that of more terrestrial species in the same family (Iguanidae).

\section{Introduction}

Marine iguanas are the only lizards that dive beneath the sea to feed. They are diurnal and at low tide feed on marine algae, mostly sea lettuce (Ulva), which grow on the rocky shores in the Galapagos. Although they will feed intertidally, they usually dive and cling to rocks 1 to $10 \mathrm{~m}$ below the surface. They ordinarily spend less than an hour feeding and pass most of the day basking in exposed locations. Other lizards may occasionally enter water or even dive to escape pursuit (Iguana iguana, Basiliscus spp., Varanus niloticus, Physignathus lesueuri), but only Amblyrhynchus feeds underwater. Darwin (1849) recognized the uniqueness of this activity and commented on its swimming and diving ability. Physiological studies of Amblyrhynchus have previously been confined to the

\footnotetext{
* Contribution No. 184 from the Darwin Biological Research Station, Isla Santa Cruz, Islas Galápagos, Ecuador.
} 
functioning of the nasal salt-secreting gland (Schmidt-Nielsen and Fänge, 1958; Dunson, 1969), thermoregulation (Bartholomew and Lasiewski, 1965; Morgareidge and White, 1969; White, 1973) and diving bradycardia (Bartholomew and Lasiewski, 1965). Measurements of metabolic function have not previously been reported.

The feeding behavior of Amblyrh ynchus imposes unusual physiological demands. Other iguanid lizards behaviorally establish a single preferred body temperature at which diurnal activities are carried out. While basking, Amblyrhynchus maintains a temperature of $35-36{ }^{\circ} \mathrm{C}$ (Bartholomew, 1966; White, 1973), a value close to the preferred body temperature of other iguanid species (Brattstrom, 1965). However, it feeds in water $10-20{ }^{\circ} \mathrm{C}$ below its basking temperature and rapidly loses heat (Bartholomew and Lasiewski, 1965; G. Wellington, pers. comm.). Most of its strenuous work must be accomplished at these lower body temperatures. The effort required to move out to sea against the wave surge can be considerable. Further exertion is required to dive to the bottom. Upon surfacing, the animals must swim back to shore and again contend with the heavy surf. This pattern of feeding requires an unusually sustained amount of activity for an iguanid, potentially complicated by the low body temperature at which it must be performed.

The physiology of activity in lizards has received considerable study (see Bennett and Dawson, 1975, for a recent review). With the exception of varanids, lizards have only modest powers for sustaining activity aerobically. Aerobic metabolic scope (the difference between standard and maximal levels of oxygen consumption) is low and tends to be maximal only near preferred body temperature (Wilson, 1974). Activity usually occurs in short bursts, supported primarily by glycolysis. Most lizards, therefore, tend to have little stamina. They exhaust within 2 to $5 \mathrm{~min}$ and require considerable time for recovery.

The interacting stressful effects of activity, diving, and temperature occasioned by the habits of Amblyrhynchus make its physiology of interest. Are its capacities for activity modified from the generalized iguanid pattern? Does it have an exceptionally high metabolic scope? Is scope maximized at the preferred body temperature $\left(\sim 35^{\circ} \mathrm{C}\right)$ or at body temperature at which it feeds $\left(<25^{\circ} \mathrm{C}\right)$ ? What is the relative contribution of anaerobic metabolism to activity and diving? Our study of the metabolic physiology of Amblyrhynchus addresses these questions. Laboratory aspects of our investigations are reported in this paper; observations relating to performance in the field are presented elsewhere (Bartholomew et al., in preparation; Dawson et al., in preparation).

\section{Materials and Methods Animal Capture and Maintenance}

Thirty-three marine iguanas were utilized. Laboratory observations were confined to yearling animals (snout-vent length, 20-25 cm; Bartholomew et al., in preparation). Mean weight of individuals studied was $489 \mathrm{~g}$ (range, $379-670 \mathrm{~g}$ ). Animals were caught by slip noose or hand $0.5-1 \mathrm{~km}$ east of the Darwin Biological Research Station on Isla Santa Cruz, and all laboratory observations were made at the Station during July, 1974. Animals were fasted in shaded outdoor cages for 2 days prior to metabolic measurements. They were marked to prevent reuse and were released into the field after experimentation. 


\section{Standard Metabolic Rate}

Oxygen consumption was measured with an open circuit system as previously described by Dawson and Fisher (1969). Three metabolic chambers, measuring $28 \mathrm{~cm}$ long with a volume of $20-251$, were fashioned from Lucite cylinders. They were equipped with thermistors for measurement of chamber temperature, electrical leads for animal stimulation, incurrent and excurrent air ports in opposite end of the chamber, and a port near the middle of the cylinder for sampling air during and immediately after stimulation.

An animal was weighed and electrical leads were attached to its thighs. It was placed in a chamber between 1 100-1200 hours CST. This chamber was covered with black cloths and placed in a thermostatically-controlled enclosure, regulated $\left( \pm 0.5^{\circ} \mathrm{C}\right)$ with a YSI Thermistemp unit. Temperatures were raised above ambient with infrared lamps connected to a variable transformer. Dry air was metered through each chamber at 500-600 $\mathrm{ml} / \mathrm{min}$. The animals were left undisturbed for 8 hrs.

Standard levels of oxygen consumption were measured at 1930-2100 hrs. Carbon dioxide and water vapor were removed from the excurrent air line by absorption with Ascarite (sodium-hydrate asbestos) and Drierite (anhydrous calcium carbonate), respectively. Oxygen concentration in the excurrent air was measured with a Beckman Model E-2 paramagnetic oxygen analyzer. Three determinations per animal were made over $30 \mathrm{~min}$ and were averaged and corrected to STP to yield standard metabolic rate.

\section{Maximal Oxygen Consumption}

Maximal rates of oxygen consumption were determined by analysis of the oxygen decrement during electrical stimulation of the animal in a closed chamber (see Bennett and Dawson, 1972).

Prior to measurement of maximal oxygen consumption, the relative humidity of the chamber was measured with a Hygrodynamics humidity sensor positioned in the excurrent air line. The chamber was then sealed by closing the incurrent and excurrent air ports. During the 5-minute period of activity, electrical shocks (D.C. 5-20 V) were delivered to the animal from a Grass stimulator. Single, 1-sec pulses were administered at a frequency which sustained vigorous movement. The number of limb flexions were counted over the course of stimulation as an index of the amount of activity.

Air samples of approximately $300 \mathrm{ml}$ were removed at 2 and 5 min after initiation of stimulation by connecting the chamber to an evacuated balloon suspended in a partially evacuated vacuum flask. Sample removal was essentially instantaneous. The air sample in the balloon was metered through Drierite for absorption of water vapor and delivered to the oxygen analyzer within $3 \mathrm{~min}$ of collection. The oxygen analyzer was standardized with dry air between test samples. Factorial concentrations of oxygen within the chambers never fell below $20 \%$. Active oxygen consumption was calculated according to the following formula and corrected to STP:

where

$$
\dot{V}_{\mathrm{O}_{\mathrm{a}}} \max =\left(V-(V) \frac{P_{s} \cdot \mathrm{RH}}{P_{B^{\prime}} \cdot 100}\right)\left(F_{\mathrm{O}_{\mathrm{q}}}^{i}-F_{\mathrm{O}_{\mathrm{z}}}^{\prime}\right)\left(\frac{1}{t W}\right)
$$

$V=$ total chamber volume less animal volume

$P_{s}=$ saturated water vapor pressure under experimental conditions

$P_{B}=$ barometric pressure

$R H=$ relative humidity

$F_{\mathrm{O}_{2}}^{i}=$ initial fractional concentration of $\mathrm{O}_{2}$

$F_{\mathrm{O}_{2}}^{f_{2}}=$ final fractional concentration of $\mathrm{O}_{2}$

$t=$ duration of interval to which $F_{\mathrm{O}_{2}}^{i}$ and $F_{\mathrm{O}_{2}}^{t}$ pertain in $\mathrm{hr}$

$W=$ body mass in $\mathrm{g}$.

\section{Blood Lactate}

After 5 minutes of stimulation, the lizard was removed from the chamber and its body temperature taken rectally with a YSI thermistor probe. The animal was allowed to rest quietly for 5-10 min after cessation of stimulation whereupon a $0.3 \mathrm{ml}$ blood sample was 
obtained by cardiac puncture. This interval was chosen because blood lactate reaches maximal levels 5-10 min after activity in other large iguanid lizards (Moberly, 1968; Bennett, 1973). The methods used for blood sampling did not induce any significant lactate formation (Bartholomew et al., in preparation). Aliquots of blood were precipitated immediately with $0.6 \mathrm{~N}$ perchloric acid and centrifuged at $3000 \mathrm{rpm}$. Upon return to the United States, lactate samples were analyzed with biochemical kits manufactured by Boehringer Mannheim Corporation.

To secure control values of blood lactate for resting individuals, blood samples were obtained from two groups of animals left undisturbed for approximately 8 hours at 25 and $35^{\circ} \mathrm{C}$, respectively. None of the animals struggled during the $15 \mathrm{sec}$ or less required for sampling.

\section{Statistics}

Linear and polynomial equations calculated for this study are the best least squares fit to the data. If a function was not linearized by logarithmic transformation, polynomial regressions of increasingly higher degree were computed until no further significant improvement ( $P<0.05$ by $F$ test) was obtained. In practice, quadratic polynomials were the highest order required. Mean comparisons of two samples are made by Student's $t$-test; intergroup comparisons of more than two groups are done by Kruskall-Wallis tests. Confidence limits of $95 \%$ are used to determine significance.

\section{Results \\ Aerobic Metabolism}

Measurements of oxygen consumption integrated over 5 min of activity and standard values are plotted as functions of body temperature in Fig. 1. Standard oxygen consumption for the interval $24.2-41.6{ }^{\circ} \mathrm{C}$ has ${ }^{2} Q_{10}$ of 2.90 and is best described by the relation:

$$
\log \dot{V}_{\mathrm{O}_{\mathrm{a}}}=-2.6327+0.0463 T_{b}(n=33 ; r=0.95)
$$

where $\dot{V}_{\mathrm{O}_{2}}$ is standard oxygen consumption in $\mathrm{ml} \mathrm{O}_{2} / \mathrm{g} \cdot \mathrm{hr}$, and $T_{b}$ is body temperature in degrees Celsius. The fit of higher order polynomials does not significantly improve the description of the data $(P>0.05)$.

The data on oxygen consumption during activity are better described by a quadratic polynomial [Eq. (2)] than by either a linear or higher order polynomial regression.

$$
\begin{gathered}
\log \dot{V}_{\mathrm{O}_{2}} \max =-4.1747+0.224 T_{b}-0.00307 T_{b}{ }^{2} \\
(n=24 ; r=0.83)\left(24 \leq T_{b} \leq 41.5^{\circ} \mathrm{C}\right) .
\end{gathered}
$$

Eq. (2) predicts a maximal oxygen consumption of $0.81 \mathrm{cc} \mathrm{O}_{2} / \mathrm{g} \cdot \mathrm{hr}$ at $36-37^{\circ} \mathrm{C}$.

Aerobic scope can be determined from Eqs. (1) and (2) (Table 1). Maximal aerobic scope, $0.71 \mathrm{ml} \mathrm{O} / \mathrm{g} \cdot \mathrm{hr}$, occurs at $35-36^{\circ} \mathrm{C}$, the body temperature maintained by basking animals in the field (Bartholomew, 1966; White, 1973).

Oxygen consumption measured over the 5-minute interval (Fig. 1) is partitioned in Fig. 2 into an initial 2-minute period and a remaining 3-minute period. Data are organized into four thermal categories to facilitate examination: 25,30 , 35 , and $40^{\circ} \mathrm{C}$. All the data included fall within $1.0^{\circ} \mathrm{C}$ of one or another of these temperatures; other observations are excluded. Statistical comparisons of the measurements made during the initial 2-minute and the final 3-minute periods indicate a temperature-dependent lag in the development of maximal rates of oxygen consumption by Amblyrhynchus. At 25 and $30^{\circ} \mathrm{C}$, the rate of oxygen 


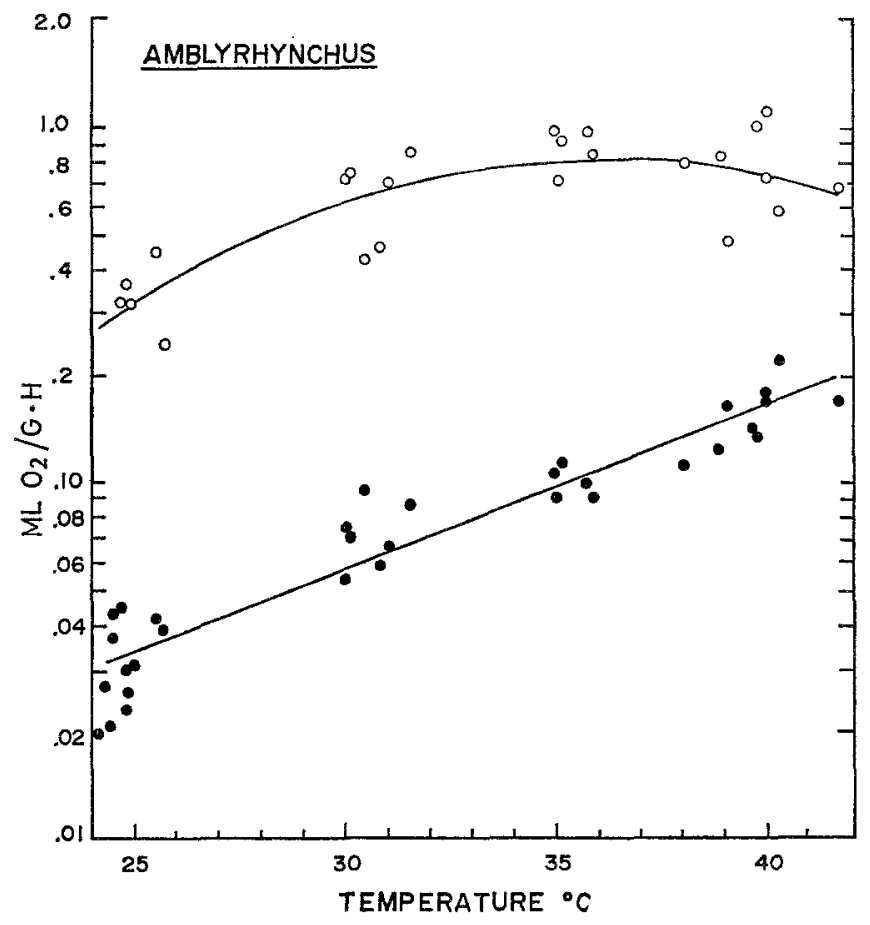

Fig. 1. The relation of oxygen consumption to temperature in Amblyrhynchus cristatus (mean weight, $489 \mathrm{~g}$ ). Standard rates $(\bullet)$ were obtained from 33 animals; rates over 5-min periods of activity elicited by electrical stimulation ( $O$ ) were recorded from 24 of these individuals. The regression lines were fitted by the method of least squares (see text)

Table 1. Aerobic scope in Amblyrhynchus cristatus at various body temperatures

\begin{tabular}{ll}
\hline $\mathrm{T}_{b}$ & Aerobic scope $^{\mathrm{a}}$ \\
\hline$\left({ }^{\circ} \mathrm{C}\right)$ & $\left(\mathrm{mI} \mathrm{O}_{2} / \mathrm{g} \cdot \mathrm{h}\right)$ \\
25 & 0.288 \\
27.5 & 0.417 \\
30 & 0.549 \\
32.5 & 0.655 \\
35 & 0.706 \\
37.5 & 0.682 \\
40 & 0.580 \\
\hline
\end{tabular}

a Calculated values from regression equations for standard and maximal oxygen consumption [Eqs. (1) and (2)].

consumption during the initial 2 minutes of stimulation is significantly lower than during the final 3 minutes $(0.02>P>0.01$ and $0.05>P>0.02$, respectively, by Student's $t$ test). Mean values during the initial 2 minutes are only half those attained during the final $3 \mathrm{~min}$. On the other hand, the rates during the two periods at 35 or $40^{\circ} \mathrm{C}$ do not differ significantly $(P>0.5)$. Maximal rates of oxygen consumption are not achieved at 25 or $30^{\circ} \mathrm{C}$ during the initial $2 \mathrm{~min}$. 


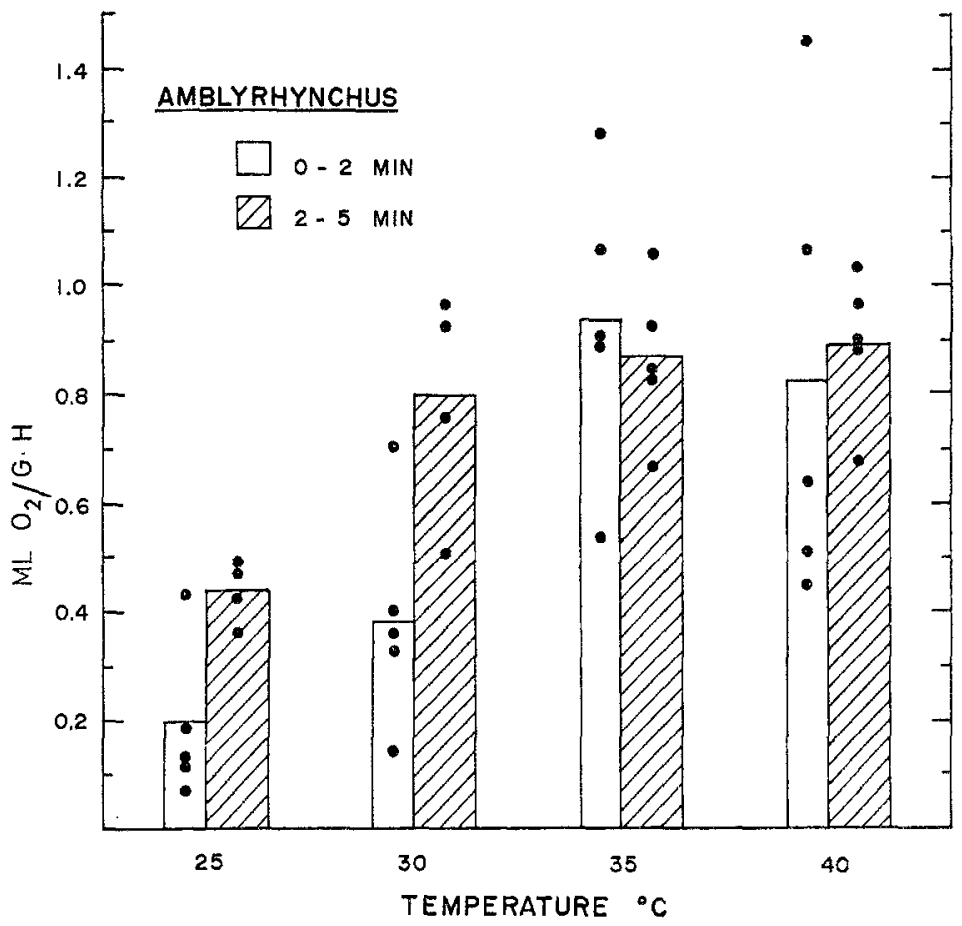

Fig. 2. The rates of oxygen consumption at different temperatures in 20 Amblyrhynchus cristatus during the initial 2 min and final 3 min of electrical stimulation

\section{Anaerobic Metabolism}

The concentrations of lactic acid in the blood 5-10 min after cessation of stimulation are reported in Fig. 3. Control values of blood lactate for unstimulated animals average $8.0 \mathrm{mg} \%$. Only a quarter of the variance in lactate concentration following activity is accounted for by body temperature $(r=0.50)$. This relationship is best described by the linear regression:

$$
\mathrm{mg} \% \text { blood lactate }=52.75+2.19 T_{b}(n=28) .
$$

The $Q_{10}$ calculated for these data amounts to only 1.2.

\section{Intensity of Activity}

The intensity of activity by lizards during the 5-minute period of stimulation was estimated from the total number of movements of the left hind limb (Fig. 4). These movements faithfully reflected the escape attempts of the animals; however, they do not necessarily indicate the power output of the animals during struggling. The amount of activity sustained during the 5-minute stimulation period does not vary significantly with body temperature $(P>0.2 ; r=0.24$, $n=26$ ) when all data points are considered. Likewise when these observations are assorted into four categories, $25,30,35$, and $40^{\circ} \mathrm{C} \pm 1{ }^{\circ} \mathrm{C}$, a Kruskal-Wallis test accepts the null hypothesis of no difference between groups $(0.5<P<0.1)$. 


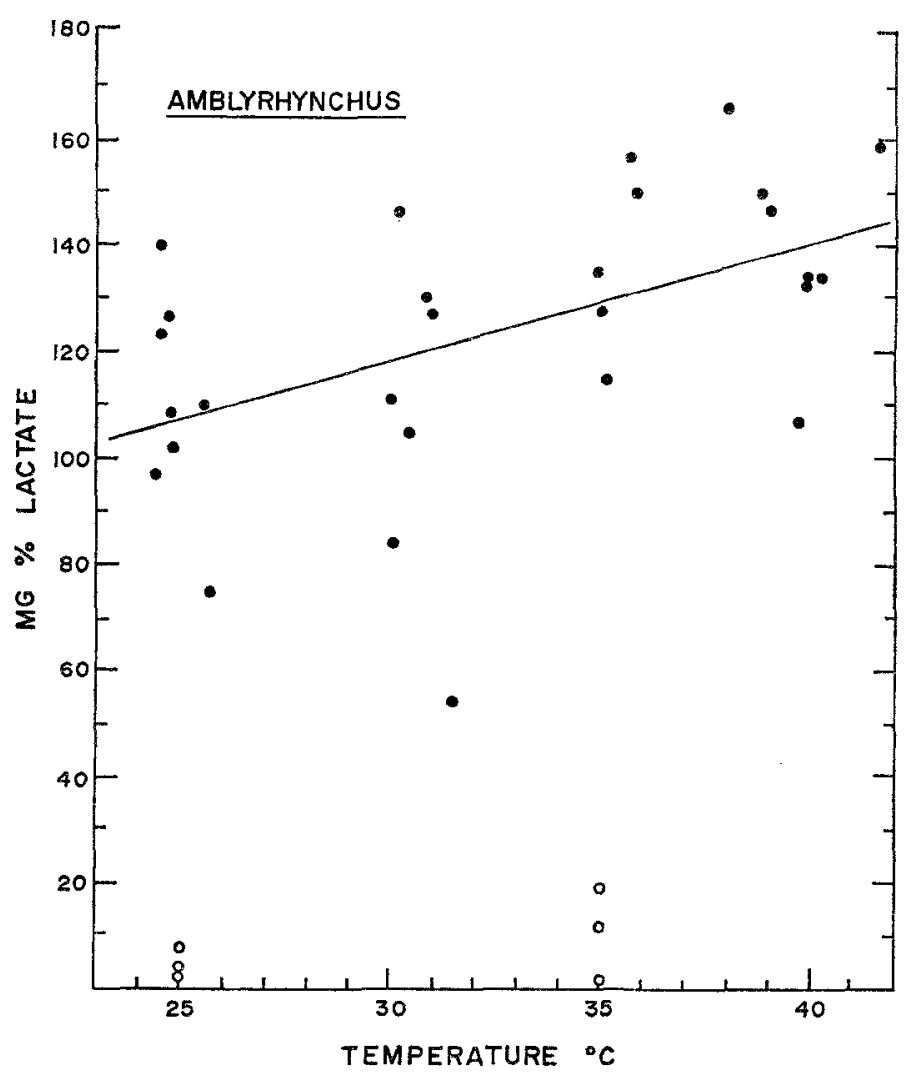

Fig. 3. Concentrations of blood lactate in Amblyrhynchus cristatus at various temperatures 5-10 min after completion of a 5-min period of electrical stimulation $(\bullet)$, and control values for animals that have rested $8 \mathrm{hr}$ in the dark (O). Each point pertains to a different individual

The time course of the response to stimulation is illustrated in Fig. 5. The amount of activity decreased during the first $2 \mathrm{~min}$ of stimulation. At all body temperatures, approximately $40 \%$ of the total response to 5 -minute stimulation occurred during the first $30 \mathrm{sec}$; nearly $90 \%$ of it took place during the first $2 \mathrm{~min}$. The animals lay quietly with only intermittent struggling during the final $3 \mathrm{~min}$ of stimulation.

Neither the total amount of activity elicited by stimulation nor its temporal pattern show any detectable thermal dependence.

\section{Discussion}

We are now in a position to address the question of whether Amblyrhynchus uses any special capacity for activity and energy metabolism in its unusual mode of life.

\section{Duration of Activity}

The pattern of activity elicited by stimulation of Amblyrhynchus resembles that reported for all other species of iguanid lizards so far examined (Iguana, 


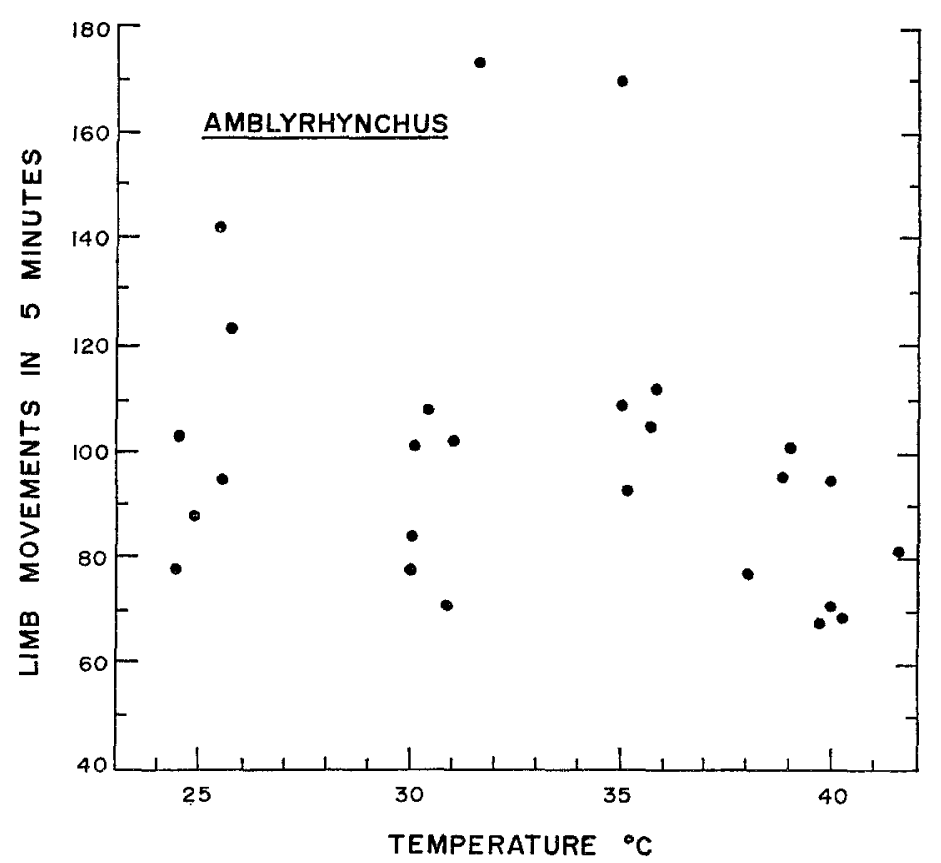

Fig. 4. Total activity of Amblyrhynchus cristatus elicited by 5 min of electrical stimulation at various temperatures. Number of limb movements in this period was used as an index of activity. Each point refers to a different individual

Moberly, 1968; Sauromalus, Bennett, 1972; Dipsosaurus, Bennett and Dawson, 1972; Anolis, Phrynosoma, Uta, Bennett and Licht, 1972; Sceloporus, Bennett and Ruben, 1975). Even when attempting to escape, iguanids sustain burst activity for only 1-2 minutes; activity thereafter is greatly reduced and the animals often appear to be totally exhausted. Marine iguanas cannot sustain activity for longer periods than other iguanids.

The capacities of marine iguanas for sustained swimming are equally restricted (Bartholomew et al., in preparation). Escape behavior by swimming individuals has two distinot components. At first the animal struggles violently, dives and swims rapidly underwater. This burst mode lasts about 2 minutes. Thereafter, the animal floats on the surface and swims in a slower cruising mode, decreasing velocity by half and thrust by an order of magnitude.

The temperature independence of activity in the laboratory indicates a capacity for escape regardless of body temperature. This independence has been previously noted for Amblyrhynchus in the field (Bartholomew, 1966). Bennett and Licht (1972) developed a functional basis for such a relationship by documenting the low temperature dependence of lactate formation in several kinds of lizards.

\section{Aerobic Metabolism}

Relations of resting and maximal oxygen consumption have been systematized for most vertebrate groups by the calculation of allometric equations relating 

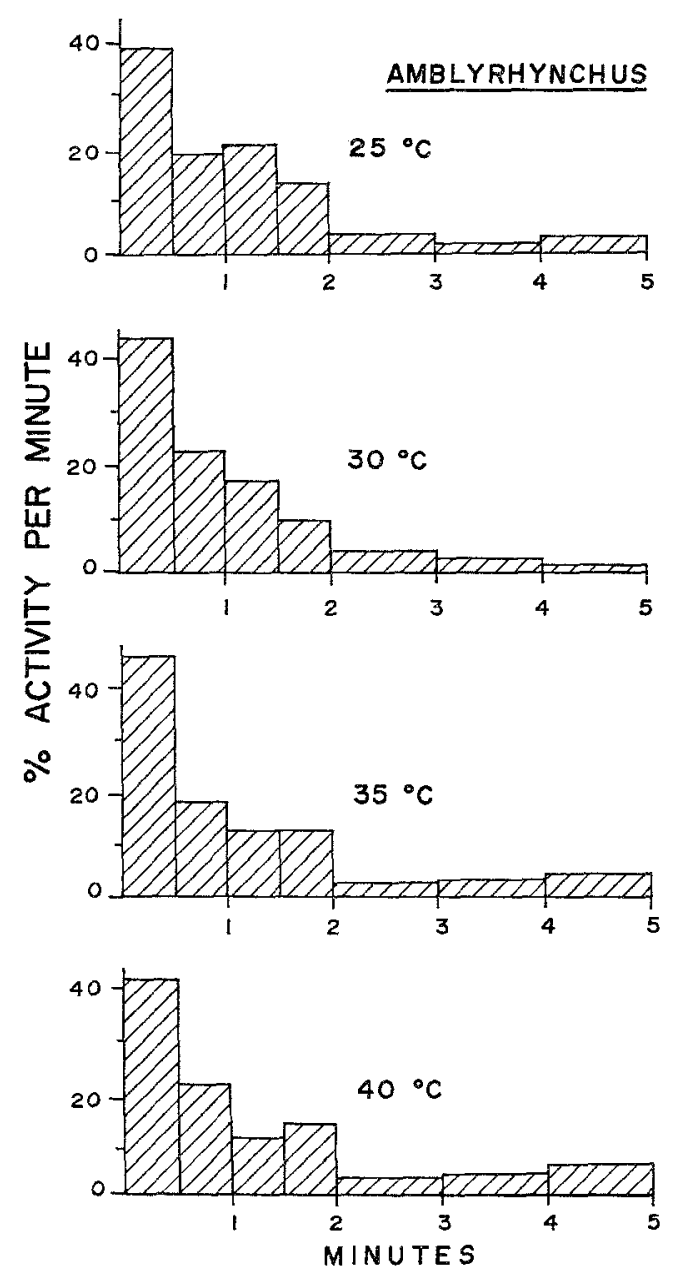

Fig. 5. Temporal distribution of the activity summarized in Fig. 4 for Amblyrhynchus cristatus at various temperatures. Each of the bars in the histogram represents the mean percentage of the activity observed in 5-8 animals during the interval to which the bar pertains

metabolism to body size at various temperatures. Such regression equations for lizards have been calculated from pertinent metabolic values by Bennett and Dawson (1975). The observed rates of standard metabolism for Amblyrhynchus are $68 \%$ and $86 \%$ of predicted values for a $489 \mathrm{~g}$ lizard at 30 and $37^{\circ} \mathrm{C}$, respectively. The fact that both percentages are low could have been anticipated because many of the values on which these equations depend pertain to lizards resting in the active rather than in the quiescent phase of their daily cycle. Pronounced circadian oscillations occur in the resting metabolic rates of lizards (see Bennett and Dawson, 1975), and these, rather than an inherently low metabolic level, probably account for the relatively low values observed in Amblyrhynchus. The value of maximal oxygen consumption at $30^{\circ} \mathrm{C}$ is $32 \%$ above the pre- 
dicted value, but this discrepancy may be the result of the accuracy permitted by our closed-chamber measurement technique. Previous observations have generally been made with open circuit systems that necessarily attenuate indications of short term fluctuations of metabolic rate. The two other studies on reptiles involving closed-chamber techniques have also reported a greater than anticipated aerobic metabolic rate (Bennett and Dawson, 1972; Gatten, 1974). With the accumulation of additional data on oxygen consumption, it will undoubtedly prove necessary to analyze data separately according to technique employed and time of day. In view of these considerations, we suggest that standard and active rates of oxygen consumption in Amblyrhynchus do not differ from those of other iguanid lizards.

The temperature dependence of maximal oxygen consumption in Amblyrhynchus resembles that of other iguanids studied (Iguana, Moberly, 1968; Sauromalus, Bennett, 1972; Dipsosaurus, Bennett and Dawson, 1972); oxygen consumption plateaus between 30 and $40^{\circ} \mathrm{C}$. Maximal oxygen consumption remains constant with increasing temperature over this range, but increasing levels of maintenance metabolism reduce aerobic scope. The latter function is maximal in Amblyrhynchus at $35-36{ }^{\circ} \mathrm{C}$, basking temperature for the species. Our data do not suggest any maximization of aerobic function at the low body temperatures occurring during swimming and diving.

The time relations of oxygen utilization by Amblyrhynchus during activity are of interest, because the temporal aspects of aerobic metabolism during muscular activity have not been previously analyzed in lizards. The rate at which maximal oxygen consumption can be attained is strongly temperature dependent. Long lag times at low body temperatures prevent a maximal aerobic contribution during the period of intensive activity (i.e., the first 2 minutes). However, maximal rates of oxygen consumption are attained during the first 2 minutes of activity at basking temperature $\left(35^{\circ} \mathrm{C}\right)$. Our data during 5 -minute stimulation at $25{ }^{\circ} \mathrm{C}$ (Fig. 2) indicate the acceleration of oxygen consumption under stimulation, but may not represent maximal levels ultimately attainable at this temperature.

Maximal rates of oxygen consumption at 25 and $30^{\circ} \mathrm{C}$ develop only after the cessation of most of the locomotor activity in Amblyrhynchus. A similar situation has been found in the amphibians $H y l a$ regilla and Batrachoseps attenuatus, in which maximal oxygen consumption may be delayed as much as 10 minutes after the completion of activity (Bennett and Licht, 1973). This displacement in time of maximal aerobic capacity and locomotor activity requires careful interpretation of the functional meaning of aerobic scope. Aerobic capacities expressed after the termination of activity may appropriately be considered a portion of the oxygen debt. Definition of the direct contribution of aerobiosis to an individual bout of activity requires that the measurement be coincident with that bout. If, on the other hand, one is interested in the maximal oxygen consumption per se or in the general process of recovery from activity, one should monitor oxygen consumption from the initiation of stimulation to the return of oxygen consumption to pre-stimulation levels. Measurements integrated over long periods contribute little to either of these physiological questions, but obviously have importance in the context of ecological energetics. 


\section{Anaerobic Metabolism}

Typical levels of blood lactate in Amblyrhynchus (105-140 mg\%) are also similar to those previously reported for other iguanid lizards. Maximal values of blood lactate after activity by Iguana iguana average $116 \mathrm{mg} \%$ and do not exceed $160 \mathrm{mg} \%$ (Moberly, 1968). Comparable values for Sauromalus hispidus at $35-40{ }^{\circ} \mathrm{C}$ are $115-180 \mathrm{mg} \%$; they are significantly lower at $25-30{ }^{\circ} \mathrm{C}$ (Bennett, 1973). Bennett and Dawson (1975) summarized published values of blood lactate for reptiles and concluded that concentrations of $4-20 \mathrm{mg} \%$ and more than $100 \mathrm{mg} \%$ are typical of resting and vigorously active animals, respectively.

The values of blood lactate elicited by electrical stimulation in the laboratory exceed those measured in free-swimming animals during escape (Bartholomew et al., in preparation). Free-swimming animals showed an increase of $60 \mathrm{mg} \%$ in blood lactate levels after $2 \mathrm{~min}$ of burst and 5 min of cruise swimming; laboratory values after 5 min of stimulation are $100 \mathrm{mg} \%$ at $25{ }^{\circ} \mathrm{C}$. Enforced quiet dives of one hr in Amblyrhynchus increased blood lactate levels by $137 \mathrm{mg} \%$.

Blood lactate is only an approximate index of the lactate production by the muscles during activity, for it can be influenced by rates of removal or release as well as by the rate of production. This ambiguity has led to the reliance on whole body analysis of lactate content for quantitative comparisons. Because of the size of Amblyrhynchus and because of their protected status, we did not attempt to obtain whole body estimates of lactate production. The very low thermal dependence of blood lactate is consistent with the conclusion that lactate production in Amblyrhynchus is temperature independent as is the case in other lizards examined, with the exception of Dipsosaurus dorsalis (Bennett and Dawson, 1972; Bennett and Licht, 1972).

\section{Relative Contributions of Aerobic and Anaerobic Metabolism to Maximal Activity}

We cannot make a precise determination of the total energetic yield derived from anaerobic metabolism because whole body lactate concentrations were not measured. However, use of simplifying but realistic assumptions about lactate formation and distribution allows us to approximate these parameters and compare them to the energetic yield of aerobic metabolism.

First, let us assume that levels of blood lactate 10 minutes after cessation of activity represent the average lactate content of the whole body at the end of stimulation. (In Anolis carolinensis, body lactate content at exhaustion is $1.46 \mathrm{mg}$ lactate/g body weight and blood lactate is $1.40 \mathrm{mg}$ lactate $/ \mathrm{ml}$ blood 10 minutes after exhausting activity at $30^{\circ} \mathrm{C}$, Bennett and Licht, 1972.) Second, we will further assume that all of the lactate appearing in the blood was formed during the first $2 \mathrm{~min}$ of stimulation, the time when over $90 \%$ of the activity was elicited (see Fig. 5). (Between $\mathbf{8 4 - 9 8 \%}$ of the total lactate produced during activity to exhaustion in the four species of lizards so far studied was formed during the first 90 seconds of activity, Bennett and Licht, 1972.)

Using these two assumptions we can estimate the relative contribution of the two metabolic modes to ATP production according to the relations specified by Bennett and Licht (1972): 
Table 2. Calculated production of ATP and carbohydrate utilization during $2 \mathrm{~min}$ of activity in Amblyrhynchus cristatus at various body temperatures. See text for basis of calculation

\begin{tabular}{|c|c|c|c|c|c|c|}
\hline \multirow{2}{*}{$\begin{array}{l}T_{b} \\
\left({ }^{\circ} \mathrm{C}\right)\end{array}$} & \multicolumn{3}{|c|}{ Net ATP formation } & \multicolumn{3}{|c|}{ Glucose-6-phosphate utilization } \\
\hline & $\begin{array}{l}\text { Aerobic } \\
(\mu \text { moles/g) }\end{array}$ & $\begin{array}{l}\text { Anaerobic } \\
(\mu \text { moles } / g)\end{array}$ & $\begin{array}{l}\% \text { derived } \\
\text { anaerobically }\end{array}$ & $\begin{array}{l}\text { Aerobic } \\
(\mu \text { moles } / g)\end{array}$ & $\begin{array}{l}\text { Anaerobic } \\
(\mu \mathrm{moles} / \mathrm{g})\end{array}$ & $\begin{array}{l}\% \text { derived } \\
\text { anaerobically }\end{array}$ \\
\hline 25 & 1.50 & 16.62 & 92 & 0.038 & 5.53 & 99.3 \\
\hline 30 & 3.20 & 18.45 & 85 & 0.082 & 6.60 & 98.8 \\
\hline 35 & 8.12 & 20.27 & 71 & 0.208 & 6.75 & 97.0 \\
\hline 40 & 6.34 & 22.11 & 78 & 0.163 & 7.36 & 97.8 \\
\hline
\end{tabular}

\section{$1.0 \mathrm{mg}$ lactate formed $=16.7 \mu$ moles ATP \\ $1.0 \mathrm{ml} \mathrm{O}$ (STPD) consumed $=290 \mu$ moles ATP}

Average values of oxygen consumption and lactate production are taken from Fig. 2 and 3, respectively, and net ATP yields during the first 2 min of activity are reported in Table 2. Anaerobiosis dominates ATP production at all body temperatures, and aerobiosis makes its greatest contribution at basking temperature $\left(35^{\circ} \mathrm{C}\right)$.

If all oxygen consumption were the result of glucose or glycogen catabolism, the amounts of these compounds entering either the aerobic or anaerobic pathway could be estimated according to the relationships:

$$
\begin{gathered}
\mathrm{mg} \text { lactate } \times 5.56=\mu \text { moles glucose- } 6 \text {-phosphate } \\
\mathrm{ml} \mathrm{O} \text { (STPD) } \times 7.44=\mu \text { moles glucose- } 6 \text {-phosphate }
\end{gathered}
$$

These relationships assume that 2 moles of lactate are produced or 6 moles of oxygen are utilized during the catabolism of 1 mole of glucose-6-phosphate. Between $97.0 \%\left(35{ }^{\circ} \mathrm{C}\right)$ and $99.3 \%\left(25^{\circ} \mathrm{C}\right)$ of the carbohydrates utilized during maximal activity in Amblyrhynchus enter anaerobic pathways (Table 2). We, therefore, conclude that burst activity in these animals is almost exclusively anaerobic and that aerobic metabolism is best considered as a recovery phenomenon.

\section{Conclusions}

Despite its energetically demanding feeding and unusual thermal regime, Amblyrhynchus cristatus appears typical of large iguanid lizards in its activity physiology. Its levels of both aerobic scope and anaerobic capacity are almost identical to those of other species. Maximal oxygen consumption is greatest between 30 and $40{ }^{\circ} \mathrm{C}$ and maximal aerobic scope occurs at basking temperature, $35-36{ }^{\circ} \mathrm{C}$. Aerobic scope is low at $25^{\circ} \mathrm{C}$, a typical feeding temperature at which considerable exertion is required. In addition, maximal oxygen consumption is reached quite slowly at this temperature. Amblyrhynchus relies primarily upon anaerobiosis during burst activity but does not appear to generate higher levels of lactate production than do other lizards. Its work capacity should be no greater than that of other iguanids, a condition consistent with our field observations. The activity physiology of Amblyrhynchus is virtually indistinguishable from that of Iguana iguana (Moberly, 1968), which dives occasionally, or from that of Sauromalus hispidus (Bennett, 1972, 1973), which is completely terrestrial. 
The physiological patterns common to iguanid lizards apparently preadapt Amblyrhynchus to its unusual mode of life. The major specializations of this species are primarily behavioral.

We thank the Darwin Foundation and Dr. Jean Dorst, President of the Foundation, for permission to use the facilities of the Darwin Biological Research Station. The kind assistance and cooperation of the Director, Dr. Craig MacFarland, and the Manager of the Station, Mr. Rolf Sievers, are gratefully acknowledged. Financial support for this study was provided by NSF Grant GB-32947X to GAB and NSF Grant GB-25022 to WRD.

\section{References}

Bartholomew, G. A. : A field study of temperature relations in the Galapagos marine iguana. Copeia 1966, 241-250 (1966)

Bartholomew, G. A., Lasiewski, R. C.: Heating and cooling rates, heart rate and simulated diving in the Galapagos marine iguana. Comp. Biochem. Physiol. 16, 573-583 (1965)

Bennett, A. F.: The effect of activity on oxygen consumption, oxygen debt, and heart rate in the lizards Varanus gouldii and Sauromalus hispidus. J. comp. Physiol. 79, 259-280 (1972)

Bennett, A. F.: Blood physiology and oxygen transport during activity in two lizards, Varanus gouldii and Sauromalus hispidus. Comp. Biochem. Physiol. 46A, 673-690 (1973)

Bennett, A. F., Dawson, W. R.: Aerobic and anaerobic metabolism during activity in the lizard Dipsosaurus dorsalis. J. comp. Physiol. 81, 289-299 (1972)

Bennett, A. F., Dawson, W. R.: Metabolism. In: Biology of the reptilia, vol. 5 (Physiology A), (C. Gans, ed.). New York: Academic Press 1975 (in press)

Bennett, A. F., Licht, P.: Anaerobie metabolism during activity in lizards. J. comp. Physiol. 81, 277-288 (1972)

Bennett, A. F., Licht, P.: Relative contributions of anaerobic and aerobic energy production during activity in amphibia. J. comp. Physiol. 87, 351-360 (1973)

Bennett, A. F., Ruben, J.: High altitude adaptation and anaerobiosis in sceloporine lizards. Comp. Biochem. Physiol. 50A, 105-108 (1975)

Brattstrom, B. H.: Body temperatures of reptiles. Amer. Midl. Nat. 78, 376-422 (1965)

Darwin, C.: The voyage of H. M. S. "Beagle", 2nd ed. (1845)

Dawson, W. R., Fisher, C. D. : Responses to temperature by the spotted nightjar (Eurostopodus guttatus). Condor 71, 49-53 (1969)

Dunson, W. A.: Electrolyte excretion by the salt gland of the Galapagos marine iguana. Amer. J. Physiol. 216, 995-1002 (1969)

Gatten, R. E., Jr.: Effects of temperature and activity on aerobic and anaerobic metabolism and heart rate in the turtles Pseudemys scripta and Terrapene ornata. Comp. Biochem. Physiol. 48A, 619-648 (1974)

Moberly, W. R.: The metabolic responses of the common iguana, Iguana iguana, to activity under restraint. Comp. Biochem. Physiol. 27, 1-20 (1968)

Morgareidge, K. R., White, F. N.: Cutaneous vascular changes during heating and cooling in the Galapagos marine iguana. Nature (Lond.) 223, 587-591 (1969)

Schmidt-Nielsen, K., Fänge, R.: Salt glands in marine reptiles. Nature (Lond.) 182, 783-785 (1958)

White, F. N.: Temperature and the Galapagos marine iguana - Insights into reptilian thermoregulation. Comp. Biochem. Physiol. 45A, 503-513 (1973)

Wilson, K. J.: The relationship of oxygen supply for activity to body temperature in four species of lizards. Copeia 1974, 920-934 (1974)

Dr. Albert F. Bennett

Department of Developmental and Cell Biology

University of California, Irvine

Irvine, California 92664, USA

Dr. George A. Bartholomew

Department of Biology

University of California

Los Angeles, California 90024, USA
Dr. William R. Dawson

Department of Zoology

University of Michigan

Ann Arbor, Michigan 48104, USA 